\title{
Effect of adding hygroscopic salts on the analysis of the volatile fraction of cheese
}

\author{
D. Canac-Arteaga, F. Begnaud, C. Viallon and J.-L. Berdagué \\ Laboratoire Flaveur, Station de Recherches sur la Viande, INRA de Theix, 63122 Ceyrat
}

\begin{abstract}
We investigated the effect of adding hygroscopic salts on the analysis by dynamic headspace - gas chromatography mass spectrometry of the volatile fraction of cheese. We tested five salts: calcium chloride, magnesium sulfate, potassium carbonate, sodium chloride and sodium sulfate. Relative humidity of the headspace, $\mathrm{pH}$ value of the matrix, desorption of volatile components and their odor were modified differently according to the salt used. Adding magnesium sulfate or potassium carbonate respectively released carboxylic acids and amino compounds from the matrix, whereas calcium chloride restricted the overall desorption of the volatile components. Sodium sulfate and sodium chloride had little effect.
\end{abstract}

Keywords. Inorganic salts - cheese - relative humidity - volatile components - dynamic headspace.

\section{Introduction}

The dynamic headspace technique coupled with gas chromatography and mass spectrometry is frequently used to characterize the volatile fraction of food products [1-7]. However, water is very often the main volatile component and generates artefacts during the different steps of the analysis [8-10]. Several approaches to limit these artefacts have already been tested. They include acting on the sample or the adsorbent [11-14], inserting a water trap between the sample and the adsorbent [15-18], modifying injection parameters [19] or selecting a particular type of chromatographic column [20].

Water activity in the sample can be lowered simply by mixing in hygroscopic substances such as salts or sugars. To date, many studies have been conducted to evaluate the effect of such substances on the analysis of the volatile fraction of liquids such as apple juice [21], milk [22] or model aqueous solutions [23-27]. These investigations have shown that adding hygroscopic salts increases the vapor pressure and therefore the concentration of the volatile substances in the headspace of samples. However, very little work has been published on the effects of using such salts in solid or semi-solid media [28].

The objective of this work was therefore to determine whether or not the incorporation of various hygroscopic salts into cheese, which modifies both the structure and the physical and chemical properties of the product, could facilitate the analysis of its volatile fraction, and if so to what extent.

\section{Materials and methods}

\section{Samples}

Commercial wax-coated pre-portioned hard processed cheeses were selected (mini-Babybel ${ }^{\circledR}$ ). Such samples are biochemically stable, homogeneous, and have a relatively simple volatile fraction. Their water content was $48 \%$ and the relative humidity of their headspace was $72 \%$.

\section{Storage of samples}

The cheese samples in their original wax packaging were wrapped in aluminium foil, vacuum-sealed in polyethylene bags and stored at $-25^{\circ} \mathrm{C}$. Before each analysis the sample was left overnight at room temperature.

\section{Choice of salts}

Five salts were chosen for their hygroscopic properties and their low reactivity toward the matrix of the products studied: calcium chloride (ref. Merck n²388), magnesium sulfate (ref. Prolabo $\mathrm{n}^{\circ} 25$ 164.265), potassium carbonate (ref. Sigma Aldrich $n^{\circ} 20$ 961-9), sodium chloride (ref. Prolabo $\mathrm{n}^{\circ} 27810.295$ ) and sodium sulfate (ref. Prolabo $\mathrm{n}^{\circ} 28$ 114.365). The salts were dehydrated in an oven at $105^{\circ} \mathrm{C}$ before use. To determine the least quantity of salts necessary to obtain a dense homogeneous mixture with medium particle size, preliminary tests were conducted on the texture of the cheese-salt mixtures. For $4 \mathrm{~g}$ of cheese the quantities of salt to be added were: $4 \mathrm{~g}$ of calcium chloride, $2 \mathrm{~g}$ of magnesium sulfate, $6 \mathrm{~g}$ of potassium carbonate, $10 \mathrm{~g}$ 
of sodium chloride and $8 \mathrm{~g}$ of sodium sulfate. Mixing was done in a mortar. Analyses of cheese alone and cheese mixed with salts were repeated twice, making 12 analyses in all.

\section{Purge-and-trap of volatile components}

The volatile fraction of the cheese was analyzed using a Tekmar LSC 2000 purge-and-trap instrument (Cincinnati, $\mathrm{OH} 45234$, USA). $0.5 \mathrm{~g}$ of diced cheese or $0.5 \mathrm{~g}$ of each of the mixtures was placed on glass wool (reference Prolabo $\mathrm{n}^{\circ} 23$ 039.293) at the bottom of a glass extraction cartridge (height: $70 \mathrm{~mm}$, external diameter: $34 \mathrm{~mm}$ ). The extraction cell was swept with helium (purity $=99.995 \%$, Air Liquide) at a flow rate of $30 \mathrm{ml} \cdot \mathrm{min}^{-1}$. The extractions were carried out at $19^{\circ} \mathrm{C}$ for $10 \mathrm{~min}$. The adsorbent used was Tenax $60 / 80$ mesh, length $24 \mathrm{~cm}$, internal diameter $1 / 8$ inch (reference Supelco $\left.\mathrm{n}^{\circ} 2-1059-\mathrm{U}\right)$, operating temperature $30^{\circ} \mathrm{C}$.

\section{Elimination of the water retained on the adsorbent using the dry purge method}

This operation uses drying with helium to eliminate some of the water retained on the Tenax during the trapping of the volatile components. The duration of the dry purge step was set at $10 \mathrm{~min}$ as recommended by Canac-Arteaga et al. [14].

\section{Injection of volatile components into the capillary column}

The volatile components were desorbed from the Tenax at $180{ }^{\circ} \mathrm{C}$ for $5 \mathrm{~min}$ using helium (purity $=99.9995 \%$, Air Liquide) as carrier gas with a flow rate of $1.4 \mathrm{ml} . \mathrm{min}^{-1}$. They were then cryofocused at $-150{ }^{\circ} \mathrm{C}$ in a $3-\mathrm{cm}$ segment of a deactivated fused silica precolumn (internal diameter: $0.53 \mathrm{~mm}$, length: $1.5 \mathrm{~m}$, Varian) using a liquid nitrogen cooling system. Injection in splitless mode onto the chromatographic column was then carried out by heating the precolumn for $2 \mathrm{~min}$ at $225^{\circ} \mathrm{C}$. To eliminate any potential memory effects between successive analyses, the Tenax trap was then heated for $20 \mathrm{~min}$ at $180{ }^{\circ} \mathrm{C}$ (bake step).

\section{Separation, detection and identification of the volatile components}

The volatile components were separated using a capillary column (SPB5, film thickness: $1 \mu \mathrm{m}, 60 \mathrm{~m} \times 0.32 \mathrm{~mm}$, Supelco). The oven temperature program of the chromatograph (Hewlett Packard 5890) was as follows: $5 \mathrm{~min}$ isotherm at $40{ }^{\circ} \mathrm{C}$, heating at $3{ }^{\circ} \mathrm{C} \mathrm{min}^{-1}$ up to $200{ }^{\circ} \mathrm{C}$, then 2 min hold at $200{ }^{\circ} \mathrm{C}$. The volatile components were detected by mass spectrometry with electron impact at $70 \mathrm{eV}$ (Hewlett Packard 5971S). Data acquisition was set at 3 scan. $\mathrm{s}^{-1}$ applied over the ion mass range 15 to 190 a.m.u. The volatile components were identified by comparing their spectra with those of the NIST98 $129 \mathrm{~K}$, NBS $75 \mathrm{~K}$ and Wiley-6 $250 \mathrm{~K}$ data banks, using HP-ChemStation (v A.00.00, 1995, Hewlett Packard, USA) and MassLib (v 8.6-E, 1999, MSP Friedli \& Co, Koeniz CH) software and by comparing their relative retention indices with those of the data bank of Kondjoyan and Berdagué [29].

\section{Calculation of peak area}

The peak area of the volatile components (arbitrary units of area, a.u.a.) was integrated from specific ions for each of the molecules to circumvent co-elution problems. The integrations were performed with HP-ChemStation software from Hewlett-Packard. The integration parameters were as follows: initial detection threshold 8 a.u.a., initial peak width 0.2 min., minimum peak area 10000 a.u.a.

In the particular case of 3-hydroxy-2-butanone, adding certain salts strongly increased the desorption of this compound, which is already present in large amounts in the cheese. Overload of the mass spectrometer (extinction of filament) repeatedly occurred when this compound was being detected, and the signal was recorded only at the start and end of the peak. The peak area was therefore estimated from its width and the maximum abundance observed for a 3hydroxy-2-butanone peak saturating the SPB5 stationary phase.

\section{Measurement of relative humidity}

The relative humidity in the headspace of the extraction cartridge was measured using a I155CI hygrometry probe (Rotronic, Switzerland) made of a Hygromer ${ }^{\circledR}$ polymer, the dielectric properties of which vary with the humidity of the atmosphere. Continuous measurement was used during the purge-and-trap step for each product. The signal was sent to an AOIP SA32 processor equipped with AOIP LW1 software (PB Mesures, 63110 Beaumont, France). The software was used to monitor the relative humidity for $10 \mathrm{~min}$ throughout the extraction, and the plateau value of the relative humidity was recorded.

\section{Mesurement of $\mathrm{pH}$}

The $\mathrm{pH}$ was measured by means of a Schott-Geräte CG837 pH-meter (Hofheim, Germany) using a Mettler Toledo penetration electrode (Urdorf, Switzerland) filled with Xerolyt ${ }^{\circledR}$. To make measurements the electrode was dipped into the cheese, the inorganic salts in the solid state or the cheese-salt mixture and the value read off after one minute to allow equilibration.

\section{Sensory analysis}

A qualitative description of the odor of the cheese with and without added salt was made by a panel of nine judges. About $15 \mathrm{~g}$ of cheese or freshly prepared cheese-salt mixtures was placed in a container covered with aluminium foil. Each judge was given six cheese preparations (the cheese alone and the five mixtures) and asked to describe their odor using his/her own vocabulary. The descriptors most often cited were used to characterize the odor of the cheese and the five mixtures in an overall way. In addition the olfactory similarity (OS) between the initial odor of the cheese 
(reference) and that of each of the five cheese-salt mixtures was scored by the panel from $1 / 10$ (very different odor) to 10/10 (very similar odor).

\section{Statistical analysis}

The global analysis of the similarities between the different chromatographic profiles was carried out by ascending ranking: Euclidian metrix, Ward's method [30] using Statistica software (StatSoft Inc., USA, 1997).

\section{Results and discussion}

\section{Appearance and $\mathrm{pH}$ of the mixtures}

Because of widely ranging interactions between the salts and the cheese matrix it proved impossible to compare the cheese-salt mixtures on the basis of identical mass or volume compositions. Identical cheese-salt ratios always produced very different textures and appearances according the type of salt considered, ranging from sandy to hard and compact. The best cheese-salt proportions selected were sandy and very homogeneous in appearance (sodium sulfate, sodium chloride, magnesium sulfate), sandy and rather heterogeneous in terms of grain size (potassium carbonate) or powdery and strewed with very hard agglomerates of several millimeters in diameter (calcium chloride). The effect of salts on the final $\mathrm{pH}$ of the mixtures was very marked (Tab. I). According to the cheese-salt mixtures the $\mathrm{pH}$ ranged from 4.5 (magnesium sulfate) to 12.3 (potassium carbonate). The initial $\mathrm{pH}$ value of the cheeses was 5.2. The marked changes in the structure and physical and chemical properties after adding salts induced modifications of the desorption of volatile compounds, which were studied globally by analysis of the headspace of the mixtures.

\section{Effect of salts on the relative humidity of the headspace}

Mixing hygroscopic salts into cheese modified the relative humidity $(\mathrm{RH})$ of the headspace to widely ranging degrees according to the salt (Tab. I). The RH of the headspace of the unsalted cheese, which was $72 \%$, was either only slightly modified, e.g., with added sodium sulfate $(\mathrm{RH}=65 \%$, reduction by a factor of 1.1$)$, or very strongly lowered in the case of added calcium chloride (HR $=10 \%$, reduction by a factor of 7.2). Calcium chloride and potassium carbonate lowered the $\mathrm{RH}$ of the headspace of the cheese most effectively.

\section{Effect of salts on chromatography profiles}

For the same mass of mixture analyzed the total peak area and the general appearance of the chromatograms were influenced by adding salts to the cheese matrix. The chromatograms obtained with the different mixtures are presented in figure 1. They can be compared with the reference chromatogram obtained with the cheese alone. The differences observed between the chromatograms are mainly due to modifications to both the structure (increased release of the volatile compounds through increased exchange surfaces and losses during preparation of mixtures) and the physical and chemical properties of the cheeses. The chromatographic profiles closest to the reference profile were obtained with sodium chloride and sodium sulfate. Generally we noted an increase, moderate or very marked according to the salt considered, of the peaks corresponding to the most volatile compounds, as diacetyl, 3-hydroxy-2-butanone, 2heptanone, pentanal, hexanal (Tab. I). This result is due to a decrease of their solubility in the matrix. A special case is the profile obtained with magnesium sulfate which differed from the other chromatographic profiles by the occurrence of a very large acetic acid peak eluting between 8 and $11 \mathrm{~min}$. It corresponds to the lowering of the $\mathrm{pH}$ value. The surface area of this acid was 14 times greater than that of the acetic acid peak of the reference chromatographic profile (Tab. I). The injection of a large quantity of acetic acid into the capillary column led to the saturation of the phase, resulting in a raised baseline over $30 \mathrm{~min}$. The increase in the abundance of the carboxylic acids after adding magnesium sulfate is explained by the fall in the $\mathrm{pH}$ of the mixture. Adding magnesium sulfate caused the formation of magnesium hydroxide $\left(\mathrm{Mg}(\mathrm{OH})_{2}\right)$ which consumes hydroxyl ions and thus lowers the $\mathrm{pH}$. This capture of hydroxyl ions favors the release of carboxylic acids initially retained in ionic form in the cheese matrix.

Potassium carbonate caused the most changes in the chromatogram due to the strong alkalinisation of the medium and probably the beginning of the hydrolysis of the cheese matrix (Fig. 1). Between 18 and 30 min there appeared a second very poorly resolved 3-hydroxy-2-butanone peak, and between 34 and $40 \mathrm{~min}$ another cluster of co-eluted peaks. In this cluster the substance corresponding to the peak located between 38 and 40 min was not identified, but displayed close spectral similarities with a large number of amino compounds (mass spectrum presented in figure 1). No carboxylic acid was detected in the presence of potassium carbonate. The acids were probably neutralized by the salt and retained in ionic form in the matrix. The neutralization of the acids can thus explain the $\mathrm{pH}$ increase. Added calcium chloride considerably reduced the areas of the chromatograms and also caused all traces of carboxylic acid to disappear. This salt, which proved to be the most efficient water retainer, also retained most volatile components. Water-bound compounds may have been trapped in the calcium chloride hydrate lattice or lost during the preparation of the cheese-salt mixture.

The mixing of salts with the cheese revealed a fairly close relationship $(r=0.88, p<0.05)$ though of low amplitude (Tab. I) between the RH of the headspace of the cheese-salt mixtures and the area of the peak of the water injected into the capillary column. The existence of such a relation meant that the retention of water by the calcium chloride or potassium carbonate was still visible (though weak) on the chromatogram, despite a dry-purge of $10 \mathrm{~min}$. 


\section{Original articles}

Table I. Relative humidity, $\mathrm{pH}$ and list of volatile compounds in the cheese analyzed alone (ref.) and mixed with salts. For the reference, the average abundance of each volatile compound is presented. For each volatile compound of the mixtures, the average abundance was divided by the average abundance of the reference (ratios higher than 1 are presented in bold type).

\begin{tabular}{|c|c|c|c|c|c|c|}
\hline & ref & $\mathrm{ref}+\mathrm{NaCl}$ & $\mathrm{ref}+\mathrm{Na}_{2} \mathrm{SO}_{4}$ & $\mathrm{ref}+\mathrm{K}_{2} \mathrm{CO}_{3}$ & $\mathrm{ref}+\mathrm{MgSO}_{4}$ & $\mathrm{ref}+\mathrm{CaCl}_{2}$ \\
\hline relative humidity (\%) & 72 & 58 & 65 & 35 & 56 & 10 \\
\hline $\mathrm{pH}$-value of salts & & 4.2 & 5.6 & 10.8 & 3.9 & 5.6 \\
\hline $\mathrm{pH}$-value of cheese/mixtures & 5.2 & 5 & 5.8 & 12.3 & 4.5 & 5.8 \\
\hline Water & 4713 & 0.9 & 0.8 & 0.7 & 1 & 0.6 \\
\hline \multicolumn{7}{|l|}{ ALCOHOLS } \\
\hline ethanol & 1813 & 1.3 & 1.2 & 0.9 & 1.9 & 0.7 \\
\hline 2-propanol & 133 & 0.6 & 0.6 & 0.7 & 0.9 & 0.4 \\
\hline \multicolumn{7}{|l|}{ SULFUR COMPOUNDS } \\
\hline dimethyl sulfide & 21 & 0.2 & 0.1 & 0.3 & 0.3 & 0.2 \\
\hline dimethyl disulfide & 31 & 0.4 & 0.4 & 0.9 & 0.8 & 0.4 \\
\hline \multicolumn{7}{|l|}{ KETONES } \\
\hline acetone & 1807 & 0.3 & 0.2 & 0.3 & 0.3 & 0.3 \\
\hline diacetyl & 5294 & 1.2 & 3.1 & 1.5 & 3.6 & 0.4 \\
\hline 2-butanone & 2282 & 0.2 & 0.2 & 0.2 & 0.7 & 0.1 \\
\hline 2-pentanone & 83 & 0.4 & 0.3 & 0.4 & 0.7 & 0.3 \\
\hline 3-hydoxy-2-butanone & 62800 & 1.2 & 1.3 & 1.8 & 1.8 & 0.1 \\
\hline 2-heptanone & 28 & 1.1 & 1.3 & 1.2 & 1.7 & 0.8 \\
\hline 6methyl5hepten2one & 53 & 0.4 & 0.5 & 0.6 & 1.1 & 0.4 \\
\hline 2-nonanone & 8 & 0.9 & 1.1 & 0.9 & 1.4 & 0.3 \\
\hline \multicolumn{7}{|l|}{ ALDEHYDES } \\
\hline 3-methyl-butanal & 8 & 0.7 & 0.7 & 0.3 & 1.3 & 0.2 \\
\hline pentanal & 6 & 2.7 & 1.7 & 1 & 4 & 1.4 \\
\hline hexanal & 28 & 1.6 & 2 & 1 & 4.2 & 2.3 \\
\hline octanal & 16 & 1.3 & 1 & 1.1 & 2.3 & 0.7 \\
\hline nonanal & 40 & 0.6 & 0.8 & 0.2 & 0.7 & 0.4 \\
\hline decanal & 54 & 0.9 & 0.8 & 0.8 & 1.2 & 0.6 \\
\hline \multicolumn{7}{|l|}{ ACIDS } \\
\hline acetic acid & 3582 & 1.2 & 0.7 & 0 & 14.2 & 0 \\
\hline butanoic acid & 49 & 0 & 0.2 & 0 & 8.5 & 0 \\
\hline \multicolumn{7}{|l|}{ ESTERS } \\
\hline ethyl acetate & 214 & 0.2 & 0.2 & 0.3 & 0.4 & 0.2 \\
\hline butyl acetate & 22 & 0.9 & 1.3 & 1.1 & 1.6 & 0.6 \\
\hline \multicolumn{7}{|l|}{ TERPENES } \\
\hline alpha pinene & 94 & 0.6 & 0.6 & 0.5 & 2.5 & 0.5 \\
\hline beta pinene & 33 & 0.3 & 0.4 & 0.4 & 0.7 & 0.3 \\
\hline limonene & 37 & 0.5 & 0.8 & 0.8 & 0.6 & 0.7 \\
\hline \multicolumn{7}{|l|}{ AROMATICS } \\
\hline p-xylene & 17 & 2.6 & 2.2 & 1.8 & 4.5 & 2.3 \\
\hline m-xylene & 37 & 2.7 & 2.3 & 1.7 & 4.2 & 2.8 \\
\hline styrene & 36 & 0.3 & 0.3 & 0.8 & 0.3 & 0.2 \\
\hline o-xylene & 7 & 2.8 & 2.4 & 1.6 & 3 & 1.6 \\
\hline
\end{tabular}

The results of the ascending ranking showed four distinct groups of chromatograms for a similarity threshold of $75 \%$ (dotted line on the classification tree in figure 2). The first group comprises the reference profiles and the "cheese/ $\mathrm{NaCl}$ " and "cheese $/ \mathrm{Na}_{2} \mathrm{SO}_{4}$ " profiles, the similarity of which was more than $75 \%$. The three other groups form the "cheese $/ \mathrm{K}_{2} \mathrm{CO}_{3}$ ", "cheese $/ \mathrm{MgSO}_{4}$ " and "cheese $/ \mathrm{CaCl}_{2}$ " profiles. The proximity of repeats in the classification tree is a criterion of good repeatability of chromatogram shape.

\section{Effect of salts on the odor of the cheese in relation to the composition of the volatile fraction}

With no added salt the cheese had a "butter, soft-cheese, milk" odor of medium intensity. This odor was modified to a greater or lesser extent according to the salt mixed into the cheese. Correlation of the volatile fraction composition and the olfactory characteristics of the cheese (Fig. 2) shows that adding magnesium sulfate increased the desorption of most 
Reference

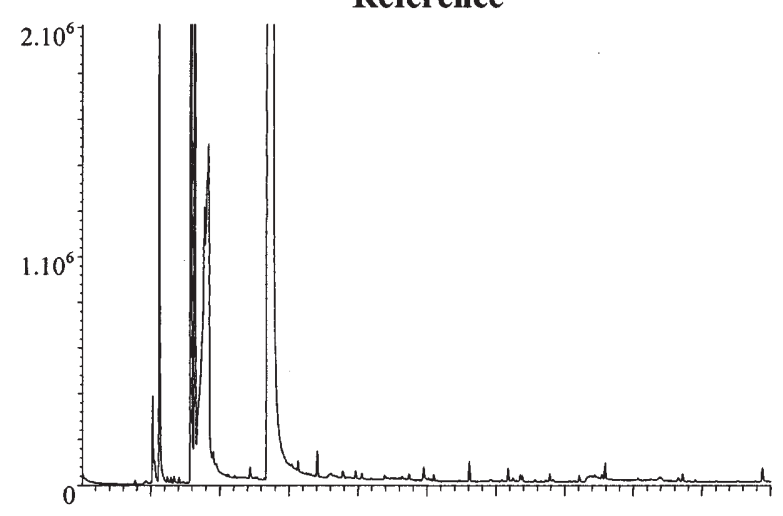

告

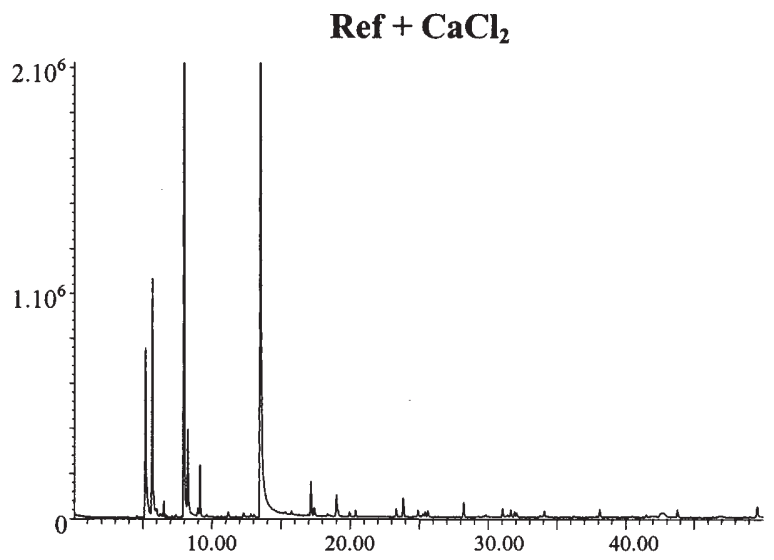

Ref $+\mathrm{Na}_{2} \mathrm{SO}_{4}$
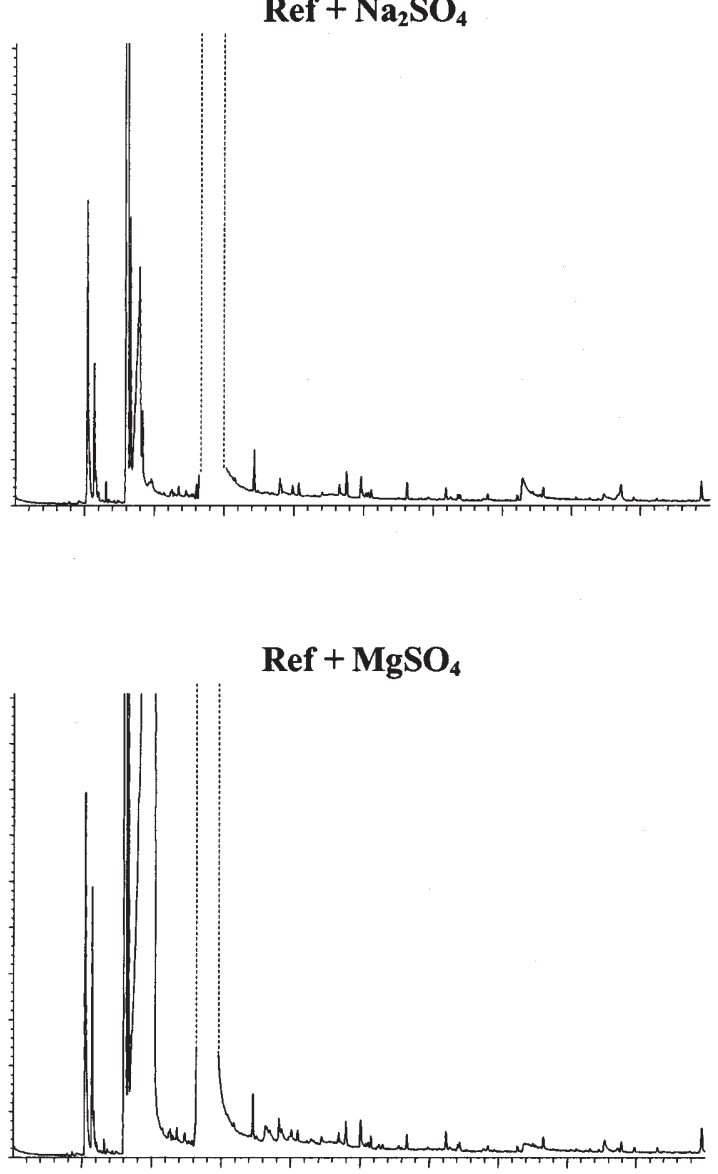

Ref $+\mathrm{K}_{2} \mathrm{CO}_{3}$

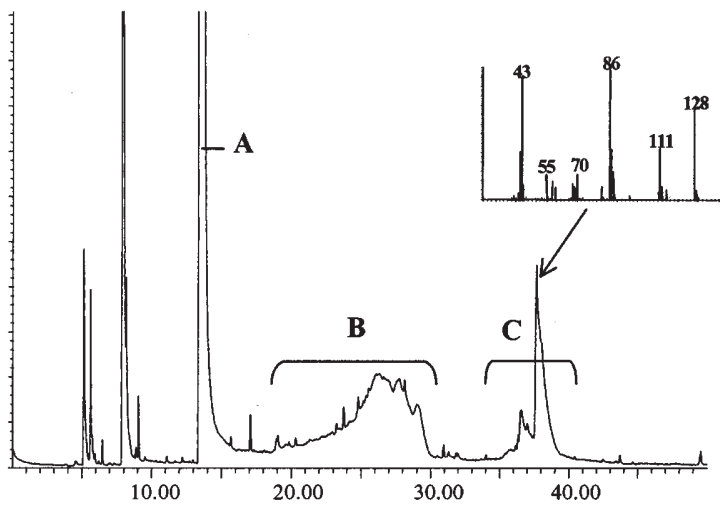

\section{Retention time (min)}

Figure 1. Chromatographic profiles of reference sample and five cheese/salt mixtures obtained by dynamic headspace-GC-MS after a 10 min purge and a 10 min dry-purge $\left(\mathrm{m} / \mathrm{z}\right.$ 33-205 a.m.u.). For the "cheese $/ \mathrm{K}_{2} \mathrm{CO}_{3}$ " mixture, "A" is the classical 3-hydroxy-2-butanone peak, "B" a second 3-hydroxy-2-butanone peak (very poorly resolved and co-eluted with compounds normally present in this part of the chromatogram), and "C" a cluster of co-eluted peaks probably containing an amine (see mass spectrum). 


\section{Original articles}

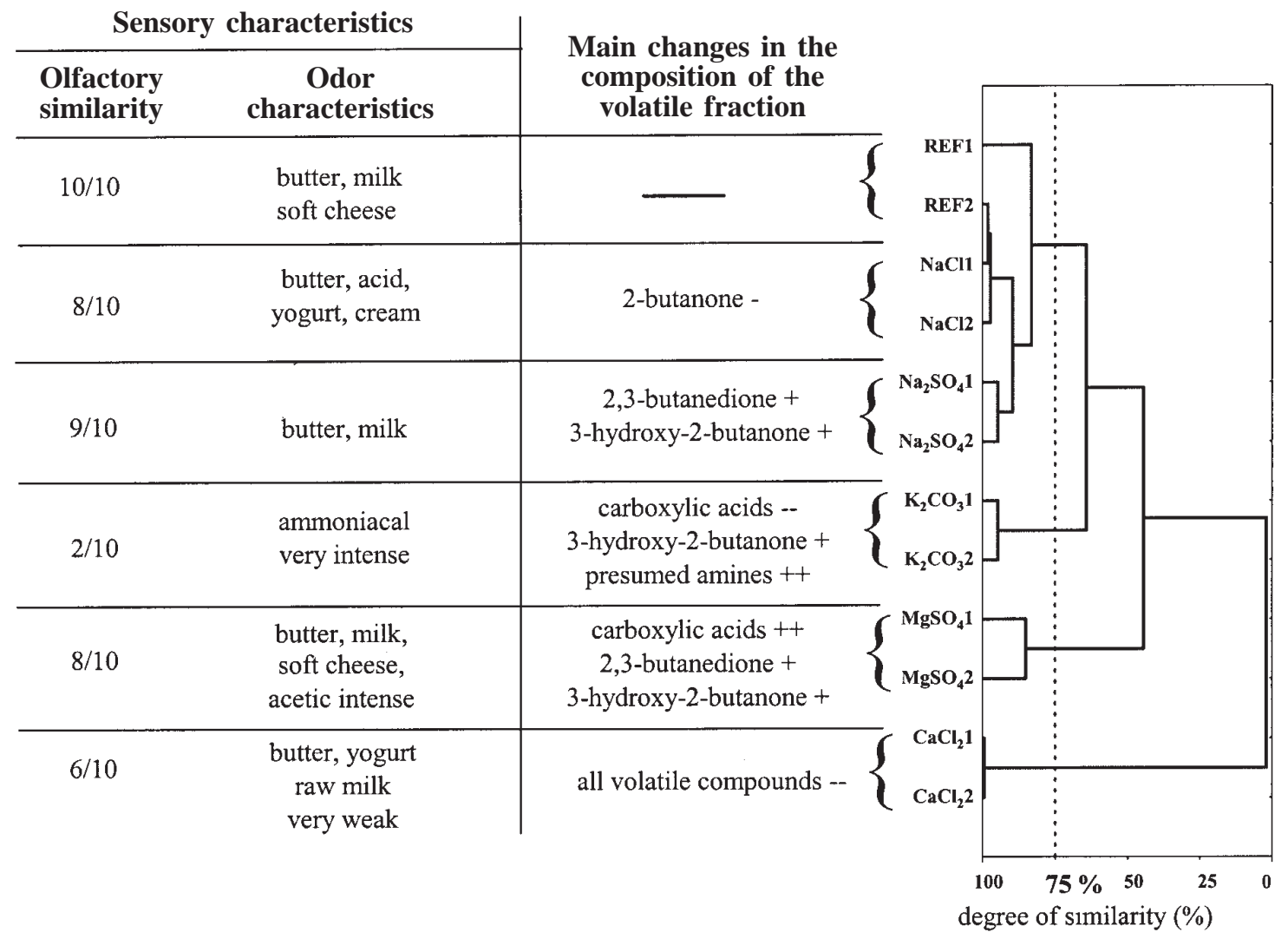

Figure 2. Hierarchical clustering of the 12 chromatograph profiles (samples of cheese alone and of cheese/salt mixtures in duplicate). Beside this classification the results are given for:

- degree of olfactory similarity (OS) between the initial odor of the cheese and the odor of each of the mixtures;

- the main odor characteristics of the cheese/salt mixtures;

- the main modifications to the volatile fraction due to the different added salts.

of the volatile cheese components, resulting in a very intense "butter, milk, soft-cheese and acetic" odor. Adding calcium chloride, which reduced the desorption of most of the volatile cheese components, resulted in a weak "butter, yogurt, raw milk" odor without any "acetic" note. In the presence of potassium carbonate the odor was very intense ammoniacal, consistent with the probable release of volatile amines and ammonia due to the alkaline hydrolysis and the high $\mathrm{pH}$ of the cheese-salt mixture. This effect was very marked during the sample preparation, but was fleeting. No ammonia or volatile amines released by potassium carbonate were detected by mass spectrometry presumably because they were lost during sample preparation. Sodium sulfate, sodium chloride and magnesium sulfate changed the olfactory characteristics of the cheese least. The olfactory similarities between the reference $(\mathrm{OS}=10 / 10)$ and the five mixtures tested indicate that the overall odors of the "cheese/sodium sulfate" (OS =9/10), "cheese/sodium chloride" $(\mathrm{OS}=8 / 10)$ and "cheese/magnesium sulfate" $(\mathrm{OS}=8 / 10)$ were very close to the overall odor of the reference cheese. The marked release of acetic acid in the pres- ence of magnesium sulfate did not modify the overall odor of the mixture relative to the reference cheese, despite the perception of very intense "butter, milk, soft-cheese and acetic" notes.

\section{Conclusion}

Addition of hygroscopic salts to a cheese matrix markedly modifies the chromatographic profiles obtained by dynamic headspace - gas chromatography - mass spectrometry. The modifications observed globally, i.e., without dissociating the impact of the modifications to the structure and physical and chemical properties of the product, revealed a strong $\mathrm{pH}$ effect on the release of certain chemical families among the volatile components. For some of them, we observed a drastic reduction of the extraction ratio. For others, the release was in contrast strongly increased. This effect could be exploited for a more specific assay of substances such as carboxylic acids and amines that are generally retained in the matrices of foodstuffs. Our results also show that if a 
dry purge step is used, adding hygroscopic salts reduces the quantity of water introduced into the chromatographic column only moderately. In food flavor studies the salt to be added to the food must be selected with care because it can distort chromatographic and olfactory results by strongly modifying desorption patterns.

\section{References}

1. Bosset, J. O.; Gauch, R. Int. Dairy Journal 1993, 3, 359-377

2. Christensen, T. C.; Hølmer, G. Milchwissenschaft 1996, 51 (3), 134-138

3. Heikes, D. L.; Jensen, S. R.; Fleming-Jones, M. E. J. Agric. Food Chem. 1995, 43, 2869-2875

4. Malundo, T. M. M.; Baldwin, E. A.; Moshonas, M. G.; Baker, R. A.; Shewfelt, R. L. J. Agric. Food Chem. 1997, 45, 21872194

5. Mateo, J.; Zumalacarregui, J. M. Meat Sci. 1996, 44, 255-273

6. Narain, N.; Hsieh, T. C.-Y.; Johnson, C. E. J. Food Sci. 1990, 55, 1303-1307

7. Ott, A.; Fay, L. B.; Chaintreau, A. J. Agric. Food Chem. 1997, 45, 850-858

8. Helmig, D.; Vierling, L. Anal. Chem. 1995, 67, 4380-4386.

9. Hinshaw, J. V. LC-GC International 1990, 3, 22,24-26.

10. Pankow, J. F. Environ. Sci. Technol. 1991, 25, 123-126.

11. Kostiainen, R. Chromatographia 1994, 38 (11/12), 709-714.

12. Helmig, D.; Vierling, L. Anal. Chem. 1995, 67, 4380-4386.

13. Gawlowski, J.; Gierczak, T.; Jezo, A.; Niedzielski, J. Analyst 1999, 124, 1553-1558.
14. Canac-Arteaga, D.; Viallon, C.; Berdagué, J. L. Analusis 1999 , 27, 780-785.

15. Noij, T.; Van Es, A.; Cramers, C.; Rijks, J. J. High Resol. Chromat. \& Chromat. Communic. 1987, 10 (2), 60-66.

16. Rosen, M. E.; Pankow, J. F. J. Chromatogr. 1991, 537, 321328.

17. Namiesnik, J.; Wardencki, W. Intern. J. Environ. Anal. Chem. 1999, 73 (4), 269-280.

18. Canac-Arteaga, D.; Viallon, C.; Berdagué, J. L. Analusis 1999, 27, 864-870.

19. Teske, J.; Efer, J.; Engelwad, W. Chromatographia 1997, 46(11/12), 580-586.

20. Vallejo-Cordoba, B.; Nakai, S. J. Agric. Food Chem. 1993, 41, 2378-2384.

21. Poll, L.; Flink, J. M. Food Chemistry 1984, 13, 193-207.

22. Urbach, G. J. Chromatogr. 1987, 404, 163-174.

23. Jennings, W. G. J. Food Sci. 1965, 30, 445-449.

24. Nelson, P.E.; Hoff, J.E. 1968, 33, 479-482.

25. Friant, S. L.; Suffet, I. H. Anal. Chem. 1979, 51 (13), 21672172.

26. Ebeler, S. E.; Pangborn, R. M.; Jennings, W. G. J. Agric. Food Chem. 1988, 36, 791-796.

27. Hino, T.; Nakanishi, S.; Hobo, T. J. Chromatogr. A 1996, 746, 83-90.

28. Degorce-Dumas, J. R.; More, J.; Goursaud, J.; Leveau, J. Y. Ind. Alim. Agric. 1984, 11-15.

29. Kondjoyan, N.; Berdagué, J.-L. A compilation of relative retention indices for the analysis of aromatic compounds; Clermont-Ferrand: Laboratoire Flaveur, 1996.

30. Ward, J.H. J. American Statistical Association 1963, 58, 236. 